\title{
ANTI-CANCER EFFECT OF CURCUMIN ON SURVIVAL AND EXPRESSION OF DNMT1 AND CDH1 GENES IN CELL LINE MIAPACA2
}

\author{
Sh.Mousavi ${ }^{1 \otimes}$, M.Azad $^{2}$, B.Rahmani $^{1}$, M.Sahmani $^{\circledR}{ }^{\bowtie}$, D.Hamedi Asl $^{1}$ \\ ${ }^{I}$ Department of Molecular Medicine, Faculty of Medical Sciences, Qazvin University of Medical Sciences, \\ Qazvin, Iran. \\ ${ }^{2}$ Department of Medical laboratory sciences, Faculty of Allied Medicine, Qazvin University of Medical \\ Sciences, Qazvin, Iran \\ 凶m.sahmani@gmail.com; shmousavi3716@yahoo.com \\ https://doi.org/10.34302/crpjfst/2021.13.3.16 \\ Article history: \\ Received: \\ 13 November 2019 \\ Accepted: \\ 1 July 2021 \\ Keywords: \\ Pancreatic cancer; \\ Curcumin; \\ Methylation; \\ Real-Time PCR; \\ DNMT; \\ CDH1. \\ ABSTRACT \\ Introduction: Pancreatic cancer is a deadly sinister cancer and the fourth \\ leading reason for death worldwide. DNMT1 is essential for the \\ conservation of the methylation landscape due to its ability to recognize \\ hemimethylated DNA and conserve methylation during somatic cellular \\ division.Ecad play a role in cellular connectivity through extracellular \\ domains, Loss of Ecad Protein, lead to loss of Intercellular Connections, \\ Provides Cell Metastasis. The pharmacological effects of curcumin include \\ inducing apoptosis, anti-cell proliferation, antioxidant and anti-angiogenesis \\ are proved and this compound has the potential to be used in cancer \\ prevention. \\ Objectives: The current study was performed in order to explore in vitro \\ antitumor activity of curcumin in human pancreatic carcinoma cell line \\ MIAPaCa2.DNMT1 and CDH1 genes expression were examined by \\ quantitative real-time PCR. Finally, the effects of curcumin on viability and \\ DNMT1 gene and CDH1 gene expression status were evaluated. \\ Method: MiaPaca-2cell line was cultured in monolayers. The cells were \\ treated with curcumin using different concentrations of 2,5, 10, 20,40, 80 \\ $\mu \mathrm{M}$ for 24,48 and 72 hours. Viability was checked by MTT assay and \\ DNMT1 and CDH genes expression was evaluated by RT-PCR. \\ Results: Our results indicate that the level of DNMT1 mRNA expression \\ was decreased after treatment. Expression level of CDH1 mRNA were \\ increased. Data obtained from MTT revealed antiproliferative effects of \\ curcumin for $20,40,80 \mu \mathrm{M}$ concentrations. \\ Conclusions: We conclude that cell viability and level of DNMT1 mRNA \\ was decreased after curcumin treatment, and level of CDH1 mRNA was \\ increased. So, These observations suggest that curcumin, a molecule with \\ varied actions, as a supplementary could be developed into an effective \\ chemopreventive and chemotherapeutic agent for pancreatic cancer \\ treatment.
}

\section{Introduction}

Pancreatic cancer is a deadly sinister cancer and the fourth leading cause of death worldwide. Despite advances in recent years in the diagnosis and treatment of this cancer, The 5-year survival rate of these patients is below $5 \%$ and has a very poor prognosis (Zhang, Liang et al. 2011), (Yin, Wang et al. 2007). By 2030, it is anticipated to be the second murderous cancer in the world (Khan, Zubair et al. 2015). The only way to treat and save these patients is to have surgery and pancreatic resection, but since the disease is diagnosed late, only 10 to $20 \%$ of patients are candidates for surgery(Gillen, Schuster et al. 2010). At the time of diagnosis $15 \%$ of patients 
are in stage 1 or $2,35 \%$ of patients are in advanced stage of the disease and $50 \%$ of patients are diagnosed with stage 4 and metastasis(Suker, Beumer et al. 2016). So pancreatic surgery and resection do not help patients much. Their 5-year survival rate is $11 \%$ to $25 \%$ and only a few months longer will survive (Alexakis, Halloran et al. 2004). Studies on the molecular mechanism of pancreatic cancer display that this disease is related to genetic and epigenetic changes(Hong, Park et al. 2011). Epigenetics is a significant topic introduced as one of the pathways controlling gene expression, determined as the changes in gene expression without any essential changes in sequences(Azad, Kaviani et al. 2013, Rahmani, Azad et al. 2017). Methylation is one of the most substantial epigenetic mechanisms, It involves the addition of a methyl group to the cytosine base after DNA copying(Issa 2007). DNA methylation is carried out by DNA methyltransferase enzymes, It contains three enzymes DNMT1, DNMT3a and DNMT3b. DNMT1 is the significant enzyme for methylation after transcription(Baylin 2005). Epigenetic changes, including DNA methylation, alter gene expression and chromatin structure and changing DNA methylation patterns has a significant role in human cancer, these changes include increased methylation of the $\mathrm{CpG}$ islands that can inactivate the tumor suppressor(Kulis and Esteller 2010). Increased dnmt1 gene expression has been observed in most pancreatic cancer patients(Li, Omura et al. 2010).

Ecad glycoprotein encoded by CDH1 gene located on chromosome q22.116 and belong to the cell adhesion molecule (CAM) family. Intracellular and $\mathrm{Ca} 2{ }^{+}$dependent protein in epithelial cells and they play a role in cellular connectivity through extracellular domains and communication with next cell cadherins and operate as a tumor inhibitor (Huber, Züllig et al. 2011),(Vesuna, van Diest et al. 2008). Loss of Ecad Protein Function through CDH1 Gene Mutation, Loss of Intercellular Connections, Provides Cell Metastasis(Norton, Ham et al. 2007).
Curcumin is a phenolic compound that is the active compound of the plant Chromoma Longa, known as turmeric. Used as a spice and a compound known in traditional medicine in many countries(Gou, Men et al. 2011). It has anti-bacterial, anti-fungal, anti-yeast, antiparasitic and anti-cancer effects(Anuchapreeda, Fukumori et al. 2012). The pharmacological effects of curcumin include apoptotic, anti-cell proliferation, antioxidant and anti-angiogenesis and this compound has the potential to be used in cancer prevention(Shehzad, Wahid et al. 2010). In addition to treating cancer as an antiinflammatory, it is also used to treat Alzheimer's disease and malaria, It targets cell DNA, RNA and cell proteins (enzymes) (Yallapu, Jaggi et al. 2012). Curcumin inhibit multiple intracellular signaling pathways. Proteins of these pathways that target the chromatin include NF- $\mathrm{BB}$, AP-1 COX-2, MMPs, EGFR, $\beta$-catenin and TNF. The anticancer effects of curcumin are related to targeting of COX-2, HER2, TNF, EGFR, Bcrabl, proteasome PI3K, AKT, Ras and NF- $\mathrm{BB}$ proteins (Kasi, Tamilselvam et al. 2016).

The current study was performed in order to explore in vitro antitumor activity of curcumin against human pancreatic carcinoma cell line MIAPaCa2 and DNMT1 gene and CDH1 gene expression was assayed by quantitative realtime PCR. Finally, the effects of curcumin on viability and DNMT1 gene and CDH1 gene expression situation were evaluated.

\section{Materials and methods \\ 2.1. Cell culture}

The MiaPaca-2 ceell line was bought from Pasteur Institute of Iran and cultured in RPMI 1640 Gibco completed with 10\% fetal bovine serum (FBS; Gibco) and 1\% antibiotic (100 $\mathrm{U} / \mathrm{ml}$ of penicillin, $10 \mathrm{mg} / \mathrm{ml}$ of streptomycin) at $37^{\circ} \mathrm{C}$ under an atmosphere of $5 \% \mathrm{CO} 2$. The cells were cultured in cell culture plates, each well containing 6x105 cells for all concentration and control.

After treatment of the cells with curcumin using a concentration of $99 \%$ ethanol we prepared dilutions $2,5,10,20,40$ and $80 \mu \mathrm{M}$. At 24,48 and 72 hours, cells were harvested and isolated from medium. 
Real-time reverse transcription-polymerase chain (real-time RT-PCR)

At a spacing of 24,48 and 72 hours, cells were harvested and isolated from medium.

using the kit iraizol RNA extraction (RNA biotechnology $\mathrm{CO}$, Isfahan, Iran), RNA was extracted, according to the manufacturers. For the quantitative analysis of RNA extraction, we used Nanodrop techniques. For cDNA synthesis, we used the RBcDNA synthesis kit (RNA biotechnology CO, Isfahan, Iran). Realtime RT-PCR was carried out using the RotorGene Q appliance (QIAGEN co.) and analyzed by Rest 2009 software.

Primers used for DNMT1 expression were designed by IDT and NCBI

(F) GTGGGGGACTGTGTCTCTGT

(R) TGAAAGCTGCATGTCCTCAC for forward and reverse respectively.

Primers used for $\mathrm{CDH} 1$ expression were designed by IDT and NCBI

(F) GGGTTAAGCACAACAGCAAC

(R) ACCTGACCCTTGTACGTGGT

Glyceraldehyde 3-phosphate dehydrogenase (GAPDH) was used as a RNA integrity control and amplified using primers

5'-CAATGACCCCTTCATTGACC-3'

5'-TGGAAGATGGTGATGGGATT-3'

for forward and reverserespectively. [22]

The cycles were as persued: $95^{\circ} \mathrm{C}$ for 5 minutes, followed by 40 cycles of denaturing at $95^{\circ} \mathrm{C}$ for 15 seconds, annealing at $60^{\circ} \mathrm{C}$ for 20 seconds and extension at $72^{\circ} \mathrm{C}$ for 20 seconds. This was followed by the final extension at $72^{\circ} \mathrm{C}$ for 10 minutes.

\subsection{MTT assay}

Cells were cultured in 96-well culture plate ( $2 \times 103$ cell $/ 200 \mu 1) .24$ hours after the culture, we replaced ambient with $0.1 \%$ ethanol as control and concentrations of 2,5,10,20,40, and $80 \mu \mathrm{M}$ curcumin. Each concentration was accomplished as a quadruplet. After 24, 48, 72 hours of treatment, cells were laundering with PBS and $50 \mu 1$ MTT solution (Sigma) was added at a concentration of $0.05 \mathrm{mg} / \mathrm{ml}$ diluted in PBS
Cells were incubated at $37^{\circ} \mathrm{C}$ for 4 hours to permit the formation of purple formazan crystals due to mitochondrial dehydrogenase activity. Then $200 \mu \mathrm{l}$ of filtered DMSO was added to each well pursued by $25 \mu 1$ glycine buffer. The absorbance of the cell suspension was measured by spectrophotometric at $570 \mathrm{~nm}$ using an ELISA reader ( BioTek ELX800, USA). Data were analysed by one-way analysis of variance ANOVA confirmed by Dunnett's multiple comparison test using Graphpad prism 8 software where $\mathrm{P}<0.05$ was considered to be statistically substantial.

\section{Results and discussions}

\subsection{Evaluation of Cytotoxic Effect Using MTT Test}

The MTT test using to estimate Metabolic acting that can be measuring the activity of a mitochondrial enzyme succinate dehydrogenase. MTT is planned for the description of a cytotoxic indicator in a cell population using a 96 well plate format.

In the present study, we applied the MTT test to evaluate the anticancer activity of Curcumin in cell line MIAPaCa-2 assay in both concentration and time-dependent manner as explained Material and methods section. As illustrated in Figure 1 the anchorage-dependent cell viability of MIAPaCa-2 cells after exposure to curcumin was decreased significantly. These data illustrate that curcumin has antiproliferative activity in pancreatic cancer cell lines.

\subsection{Real-time PCR \\ DNMT1 mRNA expression}

Our results indicate that the level of expression DNMT1 mRNA, In 24 hours for 5, $10,20,40$ and $80 \mu \mathrm{M}$ concentrations was decreased after treatment with curcumin, but not $2 \mu \mathrm{M}$. in 48 hours all of concentration was decreased and after 72 hours treatment with curcumin all of concentration was decreased (figure 2).

\subsection{CDH1 mRNA expression}

Level of expression CDH mRNA, in 24 hours for 40 and $80 \mu \mathrm{M}$ concentration was increased, but not $5,10,20 \mu \mathrm{M}$. in 48 hours for 
40 and $80 \mu \mathrm{M}$ concentration was increased. after

72 hours all of concentration was increased (figure 3).
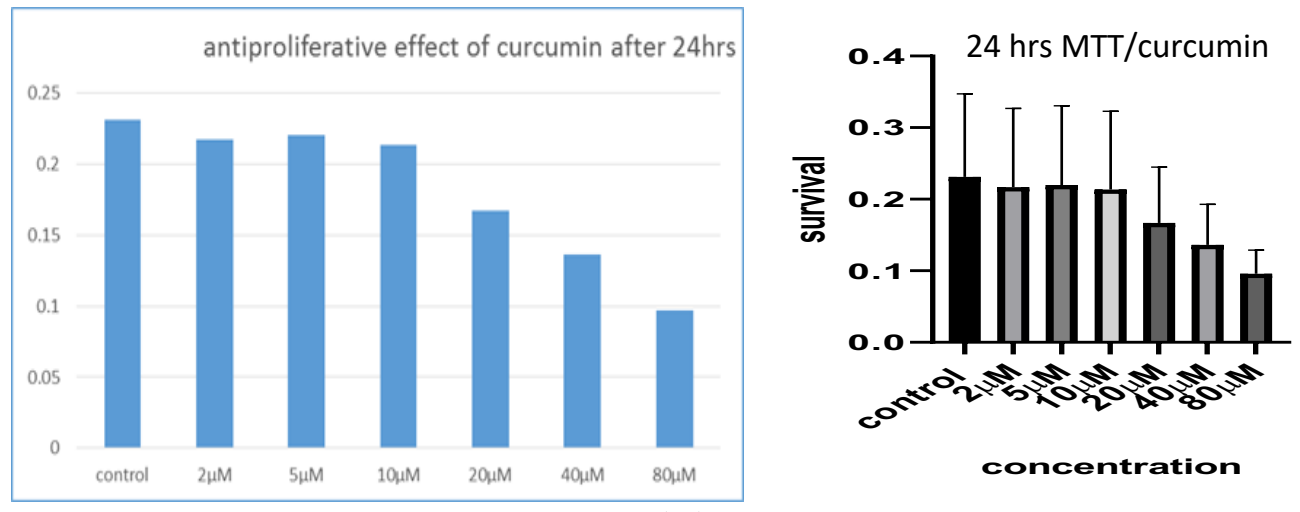

(A)

antiproliferative effect of curcumin after $48 \mathrm{hrs}$
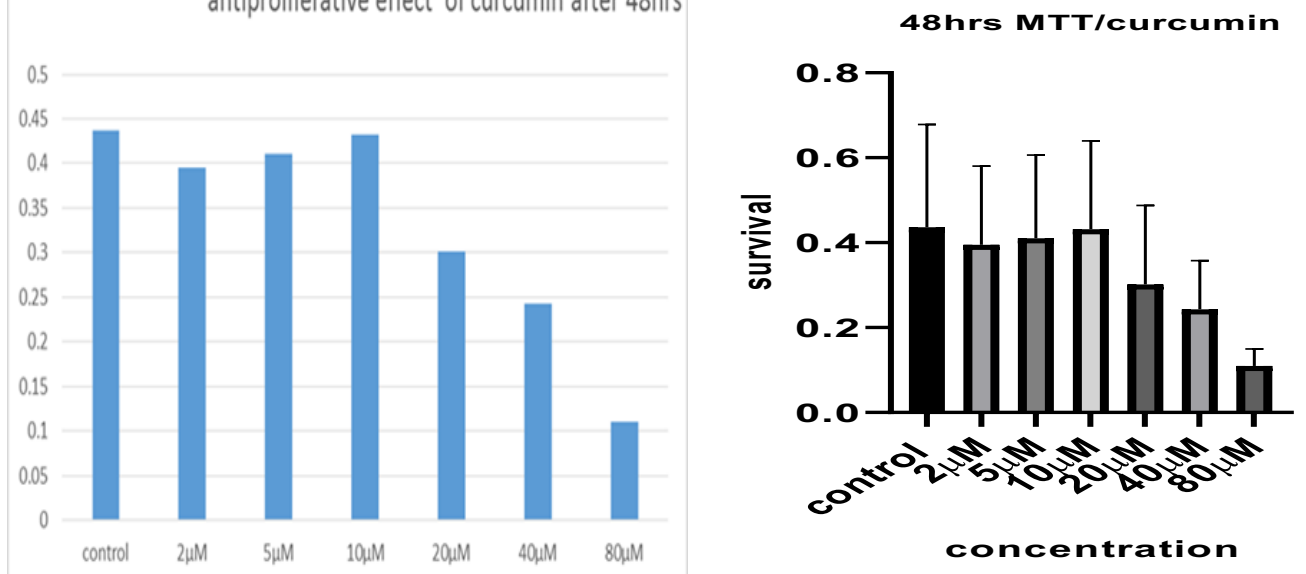

(B)
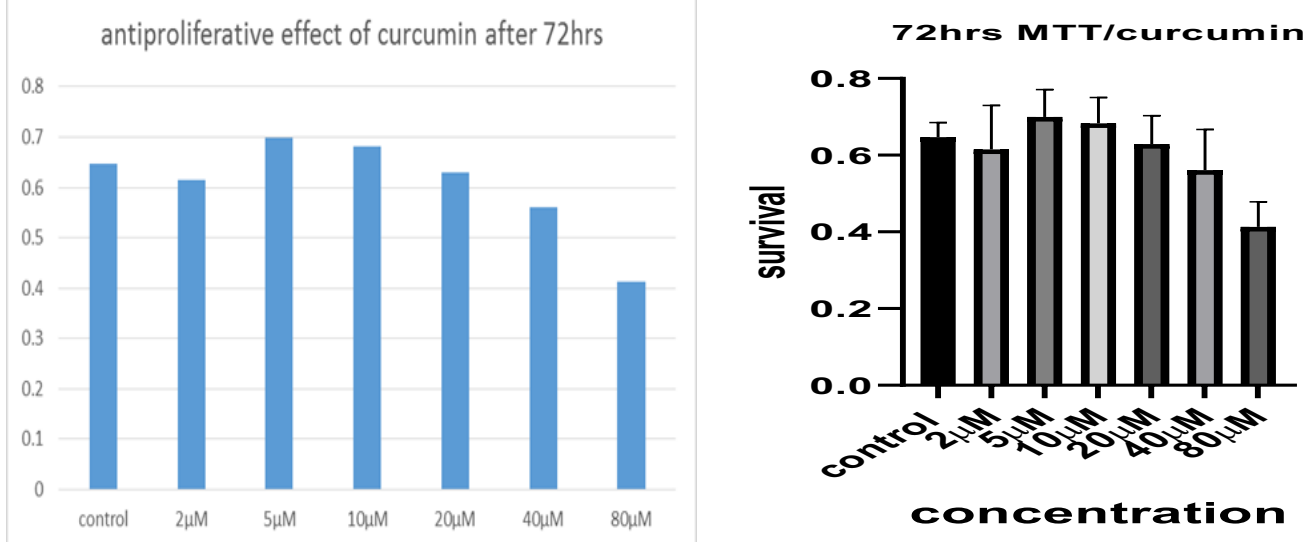

(C)

Figure 1. Anchorage-dependent cell viability of pancreatic cancer cell line (MiaPaca-2), (A) 24 hours after treatment with curcumin, (B) 48 hours after treatment with curcumin, (C) 72 hours after treatment with different concentrations $(2,5,10,20,40,80 \mu \mathrm{M})$ of curcumin. Antiproliferative effects were seen at 20 to $80 \mu \mathrm{M}$ of curcumin with a time- and concentration-dependent manner $(\mathrm{P}<0.05)$. 

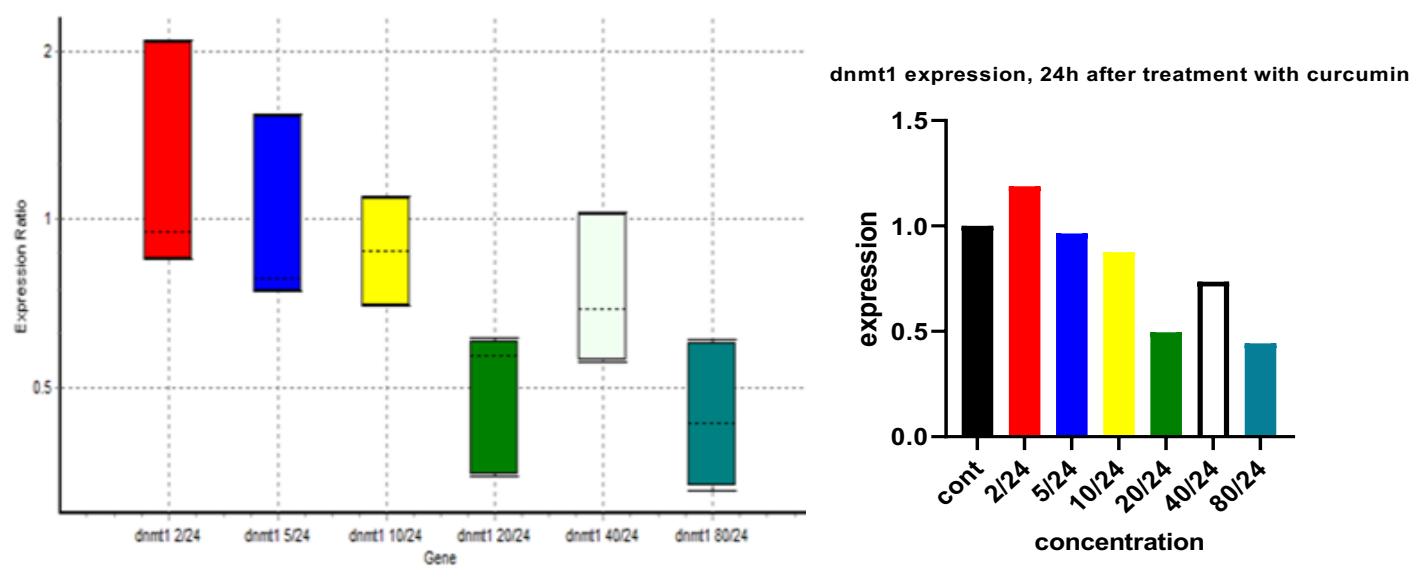

(A)

Dnmt1 expression, $48 \mathrm{~h}$ after treatment with curcumin
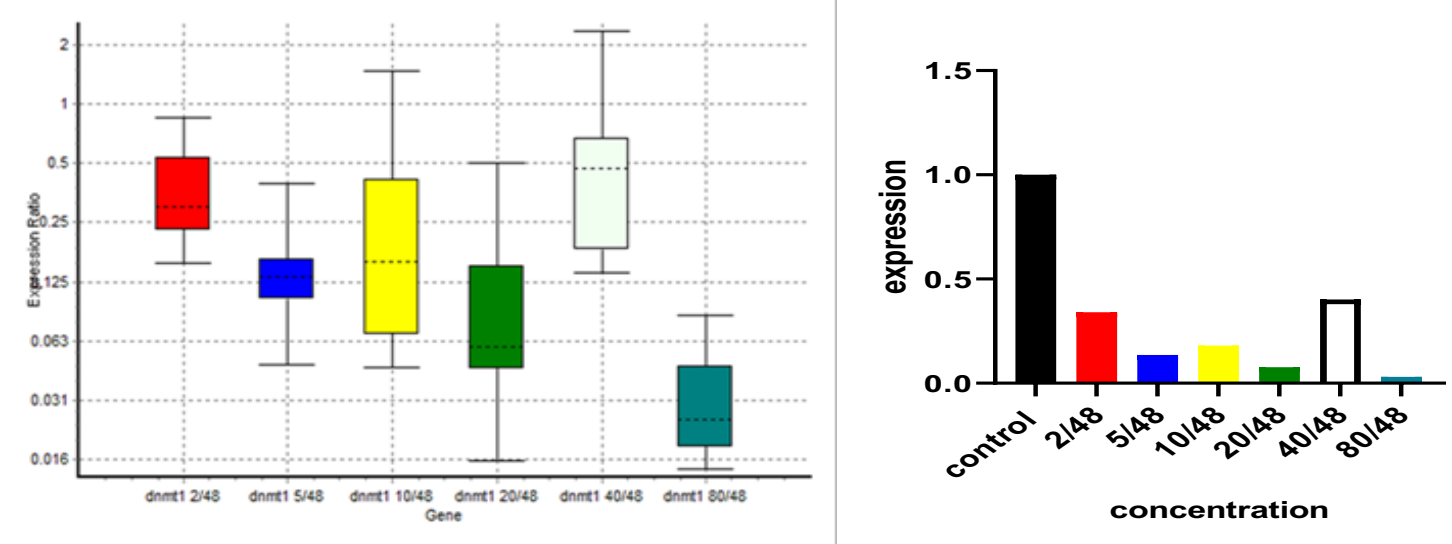

(B)

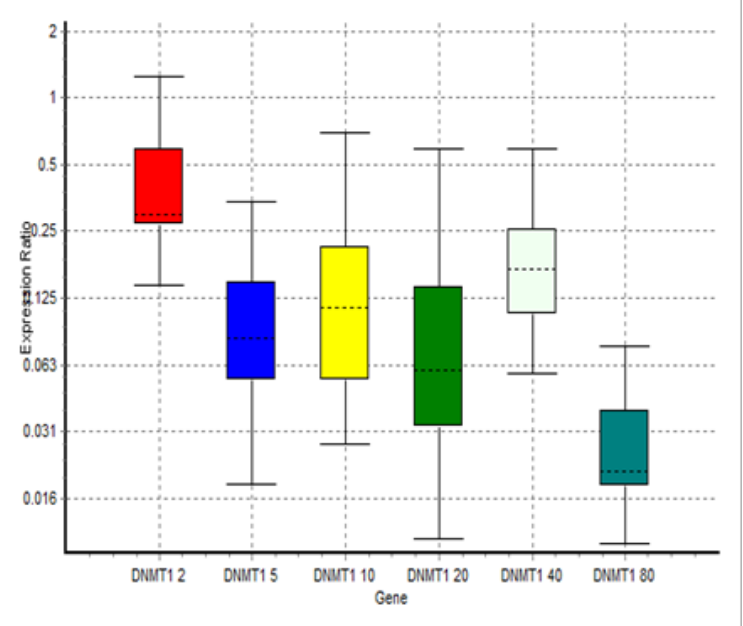

DNMT1 expression, $72 \mathrm{~h}$ after treatment with curcumin

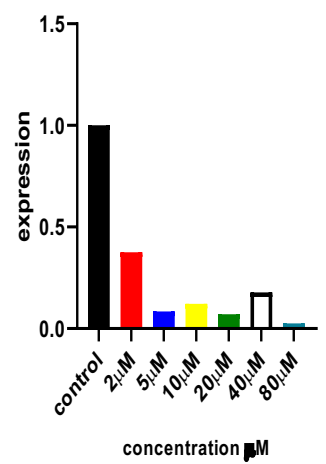

(C)

Figure 2. Detecting the transcription of DNMT1 mRNA using real-time RT-PCR. MiaPaca-2 cells were treated with 2,5, 10, 20, 40, and $80 \mu \mathrm{M}$ curcumin for 24, 48, 72 hours.(A) DNMT1 mRNA expression after $24 \mathrm{hrs}$ treated with curcumin (B) DNMT1 mRNA expression after 48 hrs treated with curcumin. (C) DNMT1 mRNA expression after $72 \mathrm{hrs}$ treated with curcumin. The levels of DNMT1 mRNA were analyzed by REST 2009 software $(\mathrm{P}<0.05)$ 


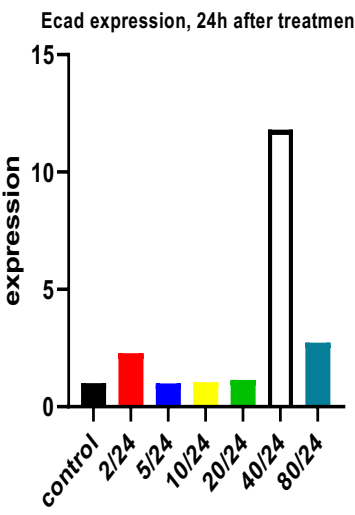

concentration

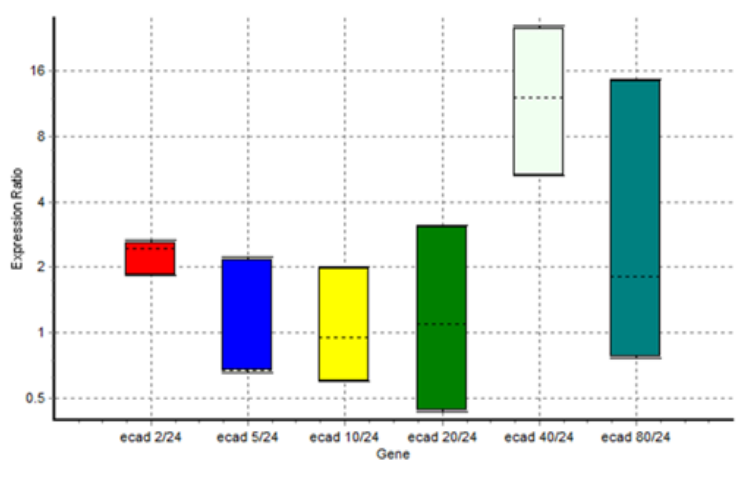

(A)

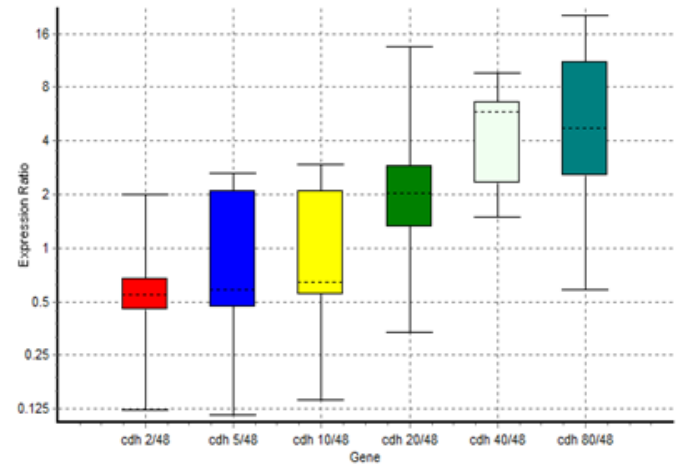

(B)

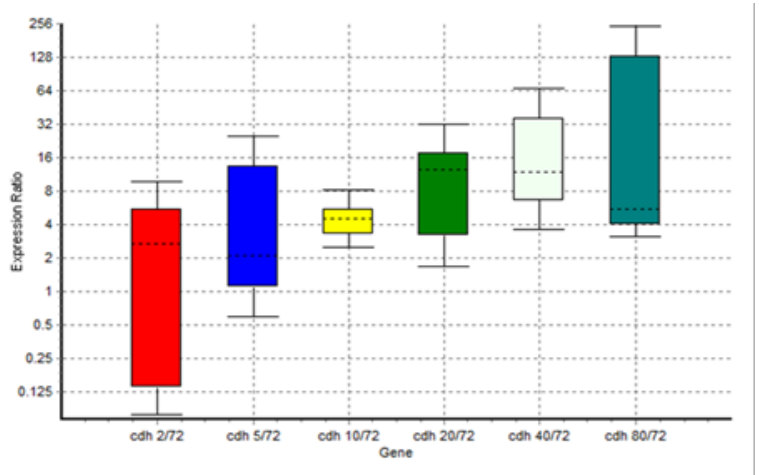

$\mathrm{CDH}$ expression, $48 \mathrm{~h}$ after treatment with curcumin

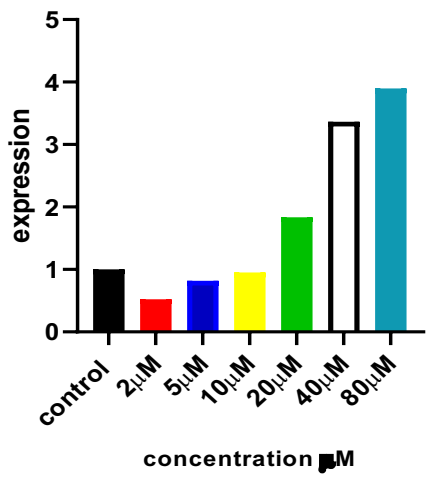

$\mathrm{CDH}$ expression, $72 \mathrm{~h}$ after treatment with curcumin

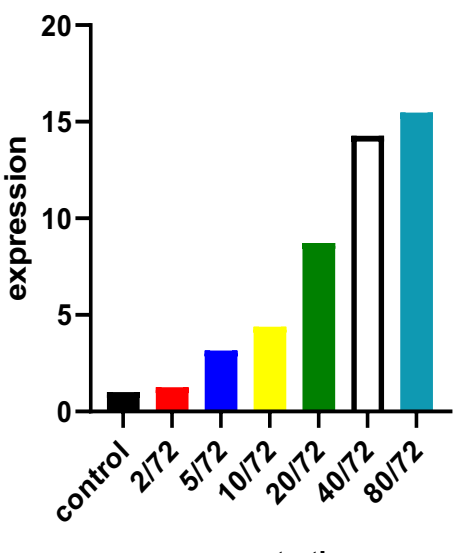

concentration

(C)

Figure 3. (A) CDH mRNA expression after $24 \mathrm{hrs}$ treated with curcumin (B) CDH mRNA expression after 48 hrs treated with curcumin. (C) CDH mRNA expression after 72 hrs treated with curcumin. The levels of CDH mRNA were analyzed by REST 2009 software $(\mathrm{P}<0.05)$ 


\subsection{Discussions}

Pancreatic cancer is an aggressive malignancy with an extremely low estimated 5year survival rate of $<2 \%$ (Sultana, Smith et al. 2007). In the metastatic stages, pancreatic cancer is never controlled by therapies and chemotherapy drugs, Effectiveness of gemcitabine as a systemic agent in the treatment of advanced stage pancreatic cancer results in a median survival of less than 6 months (Villarroel, Rajeshkumar et al. 2011). This study demonstrated changes in gene expression profiles DNMT1, CDH1 genes in pancreatic cancer cell line in response to exposure to curcumin, that have been reported in previous studies (Shishodia 2013), (Dhillon, Aggarwal et al. 2008).

Antiproliferative effect of curcumin at 20 to $80 \mu \mathrm{M}$ after 24,48 and 72 hours treatment concentrations of curcumin were seen in pancreatic cancer cell line (MiaPaca-2, respectively $(\mathrm{P}<0.05)$.

In previous study, has been illustrated inhibitory effects of curcumin observed in G2/M phase cell-cycle arrest and apoptotic cell death in a variety of cancer cells is related to inhibiting NF- $\kappa \mathrm{B}$ activation, curcumin has been displayed to suppress the expression of diverse cell survival and proliferative genes, including Bcl-2, Bcl-xL, cyclin-D1 and interleukin-6, and accordingly arrest cell cycle, inhibit proliferation, and induce apoptosis (Dhillon, Aggarwal et al. 2008),(Csaki, Mobasheri et al. 2009).

Curcumin substantialy inhibited the proliferation and survival of pancreatic adenocarcinoma, which was related with inhibition of phosphorylation of extracellular receptor kinase (ERK) 1/2, and reduction of protein expression of COX-2 and the EGFR (Zhou, S Beevers et al. 2011).

This study confirms the results of previous research, Our data demonstrated that DNMT1 gene expression is high and CDH1 gene expression is low in cell line $\mathrm{MiaPaCa} 2$ that was concordant with prior research. Treatment of Miapaca2 cells with curcumin, leading to downregulation of DNMT1 gene and upregulation of $\mathrm{CDH} 1$ gene in this cell line.
According to previous research, Improper $\mathrm{CpG}$ island hyper methylation, having been investigated in the early stages of pancreatic cancer and DNMTs protein expression, correlated with advanced stages of the tumor. In addition, high DNMTs protein expression level of patients have been seen to have rather poor survival (Huang, Chou et al. 2019), In most pancreatic cancers, DNMT1 gene expression is increased. DNMT1 gene expression contributes to cell viability, whereas, DNA hyper methylation and over expression DNMT1often inactivates tumor suppressor genes, DNMT1 gene inhibitors have been tested as a treatment for this cancer (Li, Omura et al. 2010).

CDH1 gene expression contributes to maintain an epithelial phenotype, E-cadherin was illustrated to act as an inhibitor of invasion in tumor cell lines and in in vivo tumor models. In humans, There is a strong correlation between CDH1 gene expression and survival of patients (Schmalhofer, Brabletz et al. 2009).

It has been seen in previous studies, CDH1 Gene expression has been decreased in patients with pancreatic cancer by methylation promotor , Silencing or mutation (Ottenhof, De Wilde et al. 2012). Upregulation of DNMT1gene and downregulation CDH1 genes provides conditions for inactivation tumor suppressor genes by methylation and metastasis cancer cells respectively. Based on our in vitro work displayed the activity of curcumin in cell lines of pancreatic cancer, The therapeutic agent of curcumin probably is mediated in part through the antioxidant and anti-inflammatory function of curcumin, Most studies indicate its role in inhibiting cancer tumor growth and metastasis, Curcumin is a safe and non-toxic compound even at a dose of 500-12000 mg and can be used with other anticancer compounds. (von Burstin, Eser et al. 2009, Hamzehzadeh, Atkin et al. 2018). In the future targeting specific gene for identifying people susceptible to cancer and treatment of patient with certain biomarkers, curcumin with its effect on methylation and metastasis can be used as an impressive compound in the prevention and treatment of all types of cancer. 


\section{Conclusions}

This study showed that curcumin by reducing the expression of DNMT1 can reduce methylation and also curcumin by increasing the expression of CDH1 can be used as a preventive agent and in the treatment of many cancers.

\section{References}

Alexakis, N., C. Halloran, M. Raraty, P. Ghaneh, R. Sutton and J. Neoptolemos (2004). "Current standards of surgery for pancreatic cancer." British Journal of Surgery 91(11),1410-1427.

Anuchapreeda, S., Y. Fukumori, S. Okonogi and H. Ichikawa (2012). "Preparation of lipid nanoemulsions incorporating curcumin for cancer therapy. " Journal of nanotechnology 2012.

Azad, M., S. Kaviani, M. Noruzinia, Y. Mortazavi, N. Mobarra, S. Alizadeh, M. Shahjahani, F. Skandari, M. H. Ahmadi and A. Atashi (2013). "Gene expression status and methylation pattern in promoter of P15INK4b and P16INK4a in cord blood CD34+ stem cells." Iranian journal of basic medical sciences 16(7), 822.

Baylin, S. B. (2005). "DNA methylation and gene silencing in cancer." Nature Reviews Clinical Oncology 2(S1), S4.

Csaki, C., A. Mobasheri and M. Shakibaei (2009). "Synergistic chondroprotective effects of curcumin and resveratrol in human articular chondrocytes: inhibition of IL-1 $\beta$ induced NF- $\kappa \mathrm{B}-$ mediated inflammation and apoptosis." Arthritis research \& therapy 11(6), R165.

Dhillon, N., B. B. Aggarwal, R. A. Newman, R. A. Wolff, A. B. Kunnumakkara, J. L. Abbruzzese, C. S. Ng, V. Badmaev and R. Kurzrock (2008). "Phase II trial of curcumin in patients with advanced pancreatic cancer." Clinical Cancer Research 14(14), 4491-4499.

Gillen, S., T. Schuster, C. M. Zum Büschenfelde, H. Friess and J. Kleeff (2010). "Preoperative/neoadjuvant therapy in pancreatic cancer: a systematic review and meta-analysis of response and resection percentages." PLoS medicine 7(4), e1000267.

Gou, M., K. Men, H. Shi, M. Xiang, J. Zhang, J. Song, J. Long, Y. Wan, F. Luo and X. Zhao (2011). "Curcumin-loaded biodegradable polymeric micelles for colon cancer therapy in vitro and in vivo." Nanoscale 3(4), 15581567.

Hamzehzadeh, L., S. L. Atkin, M. Majeed, A. E. Butler and A. Sahebkar (2018). "The versatile role of curcumin in cancer prevention and treatment: A focus on PI3K/AKT pathway." Journal of cellular physiology 233(10), 6530-6537.

Hong, S.-M., J. Y. Park, R. H. Hruban and M. Goggins (2011). "Molecular signatures of pancreatic cancer." Archives of pathology \& laboratory medicine 135(6), 716-727.

Huang, M.-H., Y.-W. Chou, M.-H. Li, T. E. Shih, S.-Z. Lin, H.-M. Chuang, T.-W. Chiou, H.-L. Su and H.-J. Harn (2019). "Epigenetic targeting DNMT1 of pancreatic ductal adenocarcinoma using interstitial control release biodegrading polymer reduced tumor growth through hedgehog pathway inhibition." Pharmacological research 139, 50-61.

Huber, G. F., L. Züllig, A. Soltermann, M. Roessle, N. Graf, S. K. Haerle, G. Studer, W. Jochum, H. Moch and S. J. Stoeckli (2011). "Down regulation of E-Cadherin (ECAD)-a predictor for occult metastatic disease in sentinel node biopsy of early squamous cell carcinomas of the oral cavity and oropharynx." BMC cancer 11(1), 217.

Issa, J.-P. J. (2007). "DNA methylation as a therapeutic target in cancer." Clinical Cancer Research 13(6), 1634-1637.

Kasi, P. D., R. Tamilselvam, K. SkalickaWoźniak, S. F. Nabavi, M. Daglia, A. Bishayee, H. Pazoki-toroudi and S. M. Nabavi (2016). "Molecular targets of curcumin for cancer therapy: an updated review." Tumor Biology 37(10), 1301713028.

Khan, M. A., H. Zubair, S. K. Srivastava, S. Singh and A. P. Singh (2015). Insights into the role of microRNAs in pancreatic cancer pathogenesis: potential for diagnosis, 
prognosis, and therapy. microRNA: Cancer, Springer, 71-87.

Kulis, M. and M. Esteller (2010). DNA methylation and cancer. Advances in genetics, Elsevier. 70, 27-56.

Li, A., N. Omura, S.-M. Hong and M. Goggins (2010). "Pancreatic cancer DNMT1 expression and sensitivity to DNMT1 inhibitors." Cancer biology \& therapy 9(4), 321-329.

Norton, J. A., C. M. Ham, R. Jacques Van Dam, T. A. Longacre, D. G. Huntsman, N. Chun, A. W. Kurian and J. M. Ford (2007). "CDH1 truncating mutations in the E-cadherin gene: an indication for total gastrectomy to treat hereditary diffuse gastric cancer." Annals of surgery 245(6), 873.

Ottenhof, N. A., R. F. De Wilde, F. H. Morsink, W. W. De Leng, M. G. Ausems, H. Morreau, R. Van Hillegersberg, G. J. A. Offerhaus and A. N. Milne (2012). "Pancreatic ductal adenocarcinoma in hereditary diffuse gastric cancer. A case report." Human pathology 43(3), 457-461.

Rahmani, T., M. Azad, B. Chahardouli, H. Nasiri, M. Vatanmakanian and S. Kaviani (2017). "Patterns of DNMT1 Promoter Methylation in Patients with Acute Lymphoblastic Leukemia." International Journal of Hematology-Oncology and Stem Cell Research 11(3), 172-177.

Schmalhofer, O., S. Brabletz and T. Brabletz (2009). "E-cadherin, $\beta$-catenin, and ZEB1 in malignant progression of cancer." Cancer and Metastasis Reviews 28(1-2): 151-166.

Shehzad, A., F. Wahid and Y. S. Lee (2010). "Curcumin in cancer chemoprevention: molecular targets, pharmacokinetics, bioavailability, and clinical trials." Archiv der Pharmazie 343(9), 489-499.

Shishodia, S. (2013). "Molecular mechanisms of curcumin action: gene expression." Biofactors 39(1), 37-55.

Suker, M., B. R. Beumer, E. Sadot, L. Marthey, J. E. Faris, E. A. Mellon, B. F. El-Rayes, A. Wang-Gillam, J. Lacy and P. J. Hosein (2016). "FOLFIRINOX for locally advanced pancreatic cancer: a systematic review and patient-level meta-analysis. " The Lancet Oncology 17(6), 801-810.

Sultana, A., C. T. Smith, D. Cunningham, N. Starling, J. P. Neoptolemos and P. Ghaneh (2007). "Meta-analyses of chemotherapy for locally advanced and metastatic pancreatic cancer." Journal of Clinical Oncology 25(18), 2607-2615.

Vesuna, F., P. van Diest, J. H. Chen and V. Raman (2008). "Twist is a transcriptional repressor of E-cadherin gene expression in breast cancer." Biochemical and biophysical research communications 367(2), 235-241.

Villarroel, M. C., N. Rajeshkumar, I. GarridoLaguna, A. De Jesus-Acosta, S. Jones, A. Maitra, R. H. Hruban, J. R. Eshleman, A. Klein and D. Laheru (2011). "Personalizing cancer treatment in the age of global genomic analyses: PALB2 gene mutations and the response to DNA damaging agents in pancreatic cancer." Molecular cancer therapeutics 10(1), 3-8.

von Burstin, J., S. Eser, M. C. Paul, B. Seidler, M. Brandl, M. Messer, A. von Werder, A. Schmidt, J. Mages and P. Pagel (2009). "Ecadherin regulates metastasis of pancreatic cancer in vivo and is suppressed by a SNAIL/HDAC1/HDAC2 repressor complex." Gastroenterology 137(1), 361371. e365.

Yallapu, M. M., M. Jaggi and S. C. Chauhan (2012). "Curcumin nanoformulations: a future nanomedicine for cancer." Drug discovery today 17(1-2), 71-80.

Yin, T., C. Wang, T. Liu, G. Zhao, Y. Zha and M. Yang (2007). "Expression of snail in pancreatic cancer promotes metastasis and chemoresistance." Journal of Surgical Research 141(2), 196-203.

Zhang, G.-N., Y. Liang, L.-J. Zhou, S.-P. Chen, G. Chen, T.-P. Zhang, T. Kang and Y.-P. Zhao (2011). "Combination of salinomycin and gemcitabine eliminates pancreatic cancer cells." Cancer letters 313(2), 137144.

Zhou, H., C. S Beevers and S. Huang (2011). "The targets of curcumin." Current drug targets 12(3), 332-347. 


\section{Acknowledgment}

This study was carried out in the Biotechnology Laboratory and Comprehensive Research Laboratory of Qazvin University of Medical Sciences Hospital. We are grateful to Ms. Pishkhan and Dr.Mahmoudi helping us with this project. 